\title{
DEL CUENTO AL CINE DE ANIMACIÓN: SEMIOLOGÍA DE UNA NARRATIVA DIGITAL
}

Carmen Cantillo Valero ${ }^{1}$ : Universidad Nacional de Educación a Distancia (UNED). España.

carmen.cantillo@invi.uned.es

\section{RESUMEN:}

En este ensayo se ponen bajo sospecha los discursos reproducidos a través de diferentes medios, se cuestionan sus diferencias y sus semejanzas y, hasta qué punto, pueden ser analizadas para apropiarnos de los relatos. Los cuentos, igual que el cine, los juegos y el teatro, construyen la identidad infantil, pero inos hemos detenido a pensar cuáles son las técnicas - de excitación afectiva- que se encuentran insertas en los discursos actuales?, ¿estamos educando para dar una respuesta cultural o serán las multinacionales quienes se encarguen de culturizar a la infancia? La intención de este texto, por tanto, radica en plantear cuestiones con las que desnaturalizar este tipo de ficciones para que, mediante la educación, la participación, la transgresión, la lectura perversa y la mirada alternativa y disidente recuperemos la libertad de crear nuestras historias y nuestras identidades. Sin influencias mercantilistas.

PALABRAS CLAVE: Cine de animación infantil - cuentos infantiles - educación en valores - narrativa digital - narrativa transmedia - participación.

\section{THE STORY TO FILM ANIMATION: SEMIOLOGY OF DIGITAL STORYTELLING}

\section{ABSTRACT:}

In this paper, discourses reproduced through all kinds of media are questions by analysing similarities \& differences and to what extent they can be studied to control the stories. Stories, cinema, like game, and theater, are used to build up child identity. However, have we stopped to think about the techniques -affective excitement- which are found in current practice? Are we educating our children in a culturally-responsive

\footnotetext{
${ }^{1}$ Carmen Cantillo Valero: Profesora de Comunicación y Educación en la Red en la Universidad Nacional de Educación a Distancia (UNED). Doctoranda en Educación y Comunicación en Entornos Virtuales en UNED, desarrollando una tesis sobre los estereotipos sexistas en las princesas Disney.

Correo: carmen.cantillo@invi.uned.es
} 
way or are we letting multinational companies to educate our children? The aim of this essay, therefore, is to raise questions which try to denature this type of narratives, so that, through education, participation, transgression, a different view and an alternative dissident look we may be able to recover.

KEY WORDS: Children's animated films - children's books - values education digital storytelling - participation - transmedia narrative.

\section{INTRODUCCIÓN}

Uno de los acontecimientos culturales más importantes de la década de los '50 del siglo pasado fue la aparición de diversos movimientos artísticos que pretendían provocar la participación del público. Así, aparecieron: el Performance Art, el happening artístico y otras representaciones multidisciplinares y provocativas, que instaban a la concurrencia a abandonar su posición pasiva ante la función. Este espíritu de provocación sigue vigente en la actualidad. En un mundo donde el audiovisual está omnipresente, nos movemos por un contexto cambiante en el que confluyen narrativas que discurren por artilugios diferentes, con distintas funcionalidades y grados de interacción, que nos hacen pensar que estamos ante múltiples realidades $y$, de las que también podemos formar parte. Esta percepción se amplifica en las etapas infantiles, cuando existe una mayor exposición a la influencia de este ecosistema mediático y donde los relatos tienen un peso innegable. En la narrativa audiovisual y, refiriéndose al cine infantil, Pereira (2005) expresa: "El cine, por su enorme capacidad comunicativa, influye, impresiona y conmueve a la mayoría de las personas que aceptan exponerse a su influencia" (Pereira, 2005, p. 19).

Se hace cada vez más difícil ignorar la cantidad de historias que se muestran ante nuestros ojos y que abren una ventana a un universo imaginario. Además, estas imágenes crean una narrativa que, dependiendo del dispositivo que las proyecte, será garante de una realidad distinta y reproducirá una crónica determinada, pero ¿sabemos utilizar los medios para hacer creaciones señeras que reflejen nuestra voluntad? Parece ser que no está tan claro, a pesar de que sí se abren puertas para despertar la creatividad como argumenta Henry Jenkins: "cuando la gente coge las riendas de los medios, los resultados pueden ser maravillosamente creativos" (Jenkins, 2008, p. 28).

A la vista de esta dualidad se originan algunas cuestiones que son el fundamento de este artículo y que exponemos a continuación: ¿Está en nuestras manos interpretar las narrativas que percibimos?, ¿podemos crear a partir del conocimiento o tan sólo es una "muestra" que habremos de reproducir hasta el infinito?, ¿se convertirán las nuevas narrativas digitales en el prêt-à-porter de la sociedad de masas?, ¿tenemos las personas usuarias la capacidad de crear desde la libertad o estaremos siendo influenciadas por las sombras del conocimiento?

\section{OBJETIVOS}


Estudiar las actuales narrativas digitales y provocar una reflexión crítica acerca de nuestra participación y de la "aparente" libertad que estos relatos despiertan entre el público infantil. Para ello, a lo largo del texto se plantean diversas cuestiones con las que desnaturalizar este tipo de ficciones para que, lejos de influencias mercantilistas, y mediante la educación, la participación, la transgresión, la lectura perversa y la mirada alternativa y disidente recuperemos la libertad de crear nuestras historias y nuestras identidades. Por tanto, ésta es la perspectiva de análisis convocada en este artículo.

\section{METODOLOGÍA}

Desde una perspectiva crítica y basada en el análisis cualitativo de documentos, discursos, materiales audiovisuales, etc. se propone una relación abierta e interactiva entre la teoría y la práctica. Los conceptos están en construcción y exigen un papel activo del sujeto que se aproxima a ellos, ya que nuestras reflexiones y conclusiones no tienden a la estandarización de una teoría, sino hacia la comprensión del individuo y su profundidad.

\section{DISCUSIÓN}

\subsection{La naturaleza dinámica de la narrativa digital}

Según Platón ${ }^{2}$, a cada tipo de realidad le corresponde un modelo de conocimiento e igualmente nos cuestionamos si cada medio hará una lectura diferente de la realidad.

Una historia transmedia se desarrolla a través de múltiples soportes mediáticos y con cada nuevo texto contribuye de manera distinta y valiosa para el todo. En la forma ideal de narrativa transmedia, cada medio hace lo que hace mejor, a fin de que una historia pueda ser introducida en una película, ser expandida en videojuegos o experimentado como atracción de un parque de diversiones (Jenkins, 2009, p. 135).

Este autor se refiere así a la narrativa transmedia y, recordando la transmisión oral de los grandes relatos, podríamos pensar que este concepto sólo es una moda, puesto que la narrativa analógica ya personalizaba las historias dependiendo de las personas encargadas de narrarlas. Encontramos un contraste en las palabras de Christian Salmon (2010) cuando "arroja luz sobre un gran malentendido: nosotros no construimos las historias o, mejor, no somos autores de su sentido: éste viene dado y muy acotado para que no lo forcemos ni lo cambiemos" (Salmon, 2010, p. 13).

\footnotetext{
${ }^{2}$ En el libro VII de la República de Platón, mediante la exposición del Mito de la Caverna, se explica la situación en que se encuentra el ser humano respecto al conocimiento.
} 
Sin embargo, esta idea, bien entendida y bien desarrollada, puede empoderarnos con una nueva narrativa con la que podamos crear nuestras propias historias. El primer punto distintivo parte de la diferenciación entre el medio desde el que se reproduce la narrativa (multiplataforma para Jenkins), donde encontramos una misma narración difundida en diferentes formatos, medios, momentos, etc. y la flexibilidad de un relato que, creado para ser moldeado, fluye e influye en los diversos medios en los que se re-produce.

Es importante señalar que las técnicas ficcionales aplicadas a estas narrativas muestran unos signos de identidad que se resumen en los siguientes puntos:

1. Una complicidad manifiesta de las personas usuarias que se implican hasta el extremo de llegar a formar parte de la propia narrativa, mezclándose y difuminándose en ella.

2. Una conexión constante con las obras originarias y co-creadas en un grado de correspondencia y paralelismo que consiente apreciarlas como un relato en igualdad de condiciones.

3. Se parte de narraciones previas que contemplan la reutilización, generación y apropiación de nuevas historias metavinculadas.

4. La estructura supraficcional se desarrolla a través de una secuenciación de acontecimientos que no están previamente prediseñados.

5. Un final inacabado que se propaga hasta el infinito.

La naturaleza dinámica de la narrativa digital engancha con los movimientos artísticos anteriormente descritos, situando a ambas técnicas en el mismo punto de partida, donde la meta es fácilmente alcanzable. La tarea será construir una contra-realidad con la que empoderarse de la historia.

\subsection{La fuerza del cuento y el pacto con la realidad}

Los cuentos populares se han transmitido de generación en generación a través del lenguaje hablado, existiendo varias teorías acerca de su origen; por ejemplo, "... los primeros cuentos árabes se hallan impresos en rollos de papiro desde hace más de 4.000 años" (Montoya, 2003, p. 97). La mayoría de los cuentos de la tradición oral se fueron adaptando para llegar al público infantil. En algunos casos para ajustarse a su desarrollo evolutivo $y$, en otros, para modificar la forma de algunas obras de la literatura universal que no habían sido escritas para la infancia; puesto que para que la literatura infantil apetezca tiene que contener los giros lingüísticos y la fantasía propias de la edad.

La fuerza del cuento estriba en que ni los estilos, ni los argumentos distorsionan la realidad. A lo sumo que hagan una interpretación basada en los sentimientos y pensamientos propios de la infancia. Los cuentos no abordan los mismos temas, ni tienen las mismas propiedades, ni se ajustan a categorías homogéneas; la clasificación más extendida distingue entre: cuentos maravillosos, cuentos de costumbres y 
cuentos sobre animales (Propp, 1970). Los cuentos maravillosos son los que mayormente se utilizan en la narrativa infantil porque introducen a la niña y al niño en un mundo mágico mucho más cercano que el propio mundo real que le rodea. Para Christian Salmon (2010) "La fuerza de los cuentos nunca se ha desmentido" (Salmon, 2010, p. 55) y esta influencia es utilizada como medio para la culturización por parte de algunas empresas mediáticas. La principal característica de estas narraciones es su capacidad para transmitir valores. Los cuentos clásicos contienen una moraleja que permite una mejor asimilación de las enseñanzas. Los relatos y sus personajes tienen tal autoridad en sus argumentos que cualquier explicación externa queda desplazada en el esquema mental de las criaturas. Personajes estereotipados y simples (princesas y hadas buenas frente a brujas y monstruos malvados) son mensajeros que transcienden las ideas del bien y del mal para que, en una primera etapa evolutiva, se logren aprehender los conceptos y valores que forjarán la identidad adulta.

Es sabido que la construcción de la personalidad en la infancia no está sujeta a factores genéticos, sino que viene determinada por la educación y los influjos del contexto social. En esta fase evolutiva se van desarrollando -a un ritmo vertiginosoel lenguaje, la comprensión, la inteligencia y el pensamiento. Esta etapa también se caracteriza por la elevada influencia emocional, donde resulta más complicado diferenciar lo real de lo imaginario. En este sentido, encontramos las narraciones infantiles que suelen transmitir modelos interpretativos del mundo con los que el ser humano construirá su propia identidad. El impacto que la literatura infantil puede provocar en un público ingenuo e inocente es sorprendente, llegando incluso a desarrollar fenómenos, como el eidetismo, que consiste en revivir -con absoluta claridad sensorial- sucesos anteriormente percibidos y que, curiosamente, están asociados a vivencias y situaciones con un trasfondo emocional. Como las narraciones de los cuentos o las escenas cinematográficas de alto contenido emotivo. (E. J. Anthony (1959), citado por Beltrán, Peña, Pérez y Andrés s.f.).

Los cuentos, desde siempre, han sido instrumentos para reforzar ídolos y desarrollar la imaginación. El sujeto común podía aparecer en nuestra mente con un aspecto renovado y dejar de ser corriente para convertirse en protagonista utópico de una realidad onírica. La narrativa no es algo nuevo, pero sí lo es la composición digital que forma parte del mundo actual. Un patrón similar se observa en la evolución que ha sufrido la narrativa infantil para adaptarse al contexto histórico y cultural donde las historias se han relatado, facilitando, por tanto, la internalización de la realidad exterior y provocando un engranaje libre y creativo. A estas narrativas se han ido incorporando recursos visuales que, no sólo incrementan la calidad artística de los cuentos, sino que transmiten el mensaje en un formato más próximo a la edad del público para fomentar su fantasía. Además, para un público que ha nacido y crecido utilizando los nuevos medios tecnológicos suele ser un recurso muy fácil de usar y sólo consiste en trasladar la estética del cuento para crear una narrativa no lineal "Los niños identifican muy pronto las estructuras del relato ya que tienen interiorizado el esquema narrativo de los cuentos infantiles desde edad muy temprana" (Mendoza, 2012, p. 146). 
Los relatos contemporáneos se encuentran en aplicaciones para dispositivos móviles, evolucionan y se desarrollan en las redes sociales y enfrentan a la infancia a una imagen inconcreta de sí misma. Mediante una exaltación del antropomorfismo los personajes proyectan la representación de un dogma que les perseguirá a lo largo de su vida y que se agudiza aún más cuando establece las categorías de género que impondrán la moda, marcarán los cánones de belleza y seguirán perpetuando el orden social y el "estatuto dominante" como apuntara Pierre Bourdieu (2010), "es sorprendente que el orden establecido, con sus relaciones de dominación, sus derechos y sus atropellos, sus privilegios y sus injusticias, se perpetúe, en definitiva [...] que las condiciones de existencia más intolerables puedan aparecer tan a menudo como aceptables por no decir naturales" (Bourdieu, 2010, p. 11).

En este sentido, hemos hallado aplicaciones para móviles $^{3}$ que interpretan minicuentos bajo la apariencia de pequeñas cápsulas audiovisuales para ser descargadas, compartidas en redes sociales o visionadas of-line. Estas aplicaciones suelen ofrecer material audiovisual en varios formatos, pero para los que no se plantea una metamorfosis del relato. Tan sólo son versiones digitalizadas del mismo cuento de siempre. Sin embargo, el alcance de la narrativa digital consiste en ofrecer la posibilidad de construir diversas (sub)versiones, más o menos transgresoras, ligadas a la obra original, a las que podrán incorporarse otros referentes de la tradición cultural.

Un resultado impactante lo muestran situaciones en las que ni siquiera se plantea la transformación e incorporación de las vivencias propias para que puedan formar parte de la memoria "lectora" infantil y ocupar un espacio particular en su experiencia creadora. Su diseño estanco impide que aflore la individualidad y creatividad que, en otro momento los happenings, conseguirían haciendo participar, al menos, en los detalles interpretativos de la trama.

Los personajes ficticios dejan de serlo en el momento que se personifican en nuestra realidad. Ya no hablamos sólo de la relación de la infancia con el cine, la actual cultura mediática insta a que nos relacionemos con los demás, que rememoremos las historias, que las remezclemos, que intervengamos en ellas y las compartamos en nuestras redes; aunque, como apunta Correa (2011) "si los que administran los signos también administran los significados, ¿qué parcela de interpretación o de comprensión de un mensaje nos queda?". Esta controversia se ve incrementada en la infancia, donde: "las imágenes se dirigen al mundo de las emociones, de lo intuitivo y global y es más fácil ahí pasar los filtros críticos del razonamiento" (Correa, 2011, p. 210).

\footnotetext{
${ }^{3}$ Un ejemplo es la aplicación Decuentos de la Fundación Germán Sánchez Ruipérez de Salamanca, donde se muestran una selección de vídeo-relatos narrados por personas que utilizan: objetos analógicos, sus manos, sus voces, etc. para contar los cuentos de siempre, pero que pueden ser visualizados en plataformas actuales. Disponible http://salamanca.fundaciongsr.com/940/DeCuentos-una-app-muy-entretenida (Consultado 30 de junio de 2015).
} 
$\mathrm{Si}$, como hemos visto anteriormente, las actuales narrativas nos permitiesen participar directamente también cabría la opción de buscar significados alternativos en los mensajes y, en lugar de alimentar nuestra pasividad, se fomentaría la transgresión y el cuestionamiento, donde los discursos autoritarios y las ideologías quedarían al descubierto. No obstante, las narraciones digitales infantiles están atrapando el interés de una audiencia que se siente co-creadora de los relatos porque se gestan a través de diversas estrategias narrativas, dan lugar a creaciones diferentes y proyectan funciones distintas: surgen múltiples categorías de conexión, que serán identificadas por parte de su audiencia ante la que se presenta un reto de interpretación y revisión hipernarrativo permanente: se provoca el fin de la autoría y con la aparición de la capacidad de lectura hipertextual propia de la estética posmoderna, somos testigos de la "muerte del autor" como ya aclaró Roland Barthes (2009), "la necesidad de sustituir por el propio lenguaje al que hasta entonces se suponía que era su propietario, para él, igual que para nosotros, es el lenguaje, y no el autor, el que habla" (Barthes, 2009, p. 76).

\subsection{Fantasías animadas ¿transgresoras? de ayer y hoy}

Hemos visto la "fuerza del cuento" en la construcción de la identidad infantil, pero ¿qué lectura hacemos de las creaciones que, en este sentido, encontramos en la actualidad?, ¿cómo es su narrativa?, ¿qué características tiene este mundo narrativo?, ¿podemos estructurar el proceso de expansión transmediático?, ¿de qué forma ha llegado el relato a los otros medios? y ¿su narrativa, va mutando la expresión en los procesos expansivos?, ¿qué ocurre en la fase de interpretación y la construcción de posibles mundos (Eco, 1979) al trasladarse a las redes sociales?, ¿estamos ante una verdadera narrativa digital? Para responder a estas preguntas es necesario posicionarse ante estos relatos cortos, analizar las técnicas empleadas y hacer un análisis de la interacción y transformación que se oferta a su audiencia.

A través del prisma del dibujo animado, consagrado en la memoria colectiva, el cine infantil conquista un nuevo territorio abierto a las particularidades de la sociedad y las efemérides del momento. En una época caracterizada por la sobreabundancia de discursos, que se fusionan y se disgregan continuamente, aparecen nuevas propuestas narrativas que se construyen sobre la base de la fragmentariedad, la mezcolanza, el nomadismo de géneros, el cruce de lenguajes y modelos comunicativos, ofreciendo elementos simbólicos para que, desde la infancia, se construyan: una historia, unos valores y una identidad.

Para Ricciotto Canudo, (citado por Morin, 2001, p. 15) "en el cine, el arte consiste en sugerir emociones y no en relatar hechos". Esta afirmación plantea un contrasentido si entendemos que las aventuras tienen su base en el relato $y$, dando un paso más, encontramos el concepto de "intertextualidad transmedia" de Saunders Smith, Marsha Kinder (1991) basado en la teoría original de Bakhtin (1986), que incorpora la idea de 
un diálogo donde no existe una jerarquía de importancia durante la construcción y lectura del contenido. Por tanto, habría que ubicarse desde la participación para distinguir el grado y riesgo que el público infantil, desde una posición imaginaria, realiza "evita y mutila todas las consecuencias prácticas de la participación: no hay riesgo ni compromiso para el público" (Morin, 2001, p. 87). En este sentido, y para proporcionar herramientas que ayuden al público a despertar su sentido crítico, el papel de la educación es clave.

Por otro lado, el cine animado infantil, que se crea con las características que determinan su naturaleza transmedia, debe tener la posibilidad de transformarse, de ir cambiando y moldeando su discurso según el medio en el que se desarrolle. La plataforma también va a influir en la lectura y re-escritura que evoque el relato inicial. Así, nos encontraríamos ante un mensaje que, del mismo modo que sucede con el principio de la conservación de la energía, ni se crea, ni se destruye, sólo se transforma. Y, esa conciencia crítica que venimos demando desde el principio, sería capaz de desenmascarar el adoctrinamiento hipnótico oculto en estas creaciones infantiles, que devora al público infantil transmitiéndole una falsa idea de empoderamiento.

El happening, como vimos al principio, pretendía conseguir la participación del público, las narrativas transmedias de los relatos infantiles permean en los medios y en las mentes infantiles; aunque, en estos casos, la intención va más lejos de reclamar que el público se adentre en la historia, ya que las "narrativas de consumo" se trasladan a los entornos privados (a los hogares). Sorprendentemente, contemplamos la metamorfosis que se produce en los dormitorios infantiles (sobre todo de las niñas) para erigirse en pequeños mausoleos mediáticos donde se cuida que hasta el más pequeño detalle reproduzca la decoración del palacio de la princesa que aparecía en la película; en su armario no puede faltar aquel vestido que lucía Cenicienta en el baile del príncipe; incluso, en sus fiestas de cumpleaños podemos ver trasladada toda esta estética al resto del hogar: el salón, las lámparas, los manteles, etc. todo se transforma, se comparte y se difunde en las Redes sociales por los adultos que, sin pensarlo están promocionando esta mega-excitación emocional con la que participan en la política de distribución de las grandes corporaciones mediáticas. Abren las puertas de sus casas al poder de las corporaciones para que sus hijas se pierdan en un modelo de mujer sumisa y naturalizada, para que se conviertan en Princesas.

Tal vez nos deslumbre esta hipernarrativa y seamos incapaces de establecer relaciones para descubrir dónde se esconde un mensaje manipulador y androcéntrico. Quizás, la imagen que se nos muestra del mundo sea la que nos impida ver la realidad y necesitemos una pedagogía que nos despierte del letargo de lo "novedoso" o como decía McLuhan (1998) "toda tecnología nueva disminuye así la interacción de los sentidos y la consciencia, precisamente en la nueva zona de novedad donde se produce una especie de identificación entre el observador y el objeto. Esta conformación sonambulística del observador a la nueva estructura hace a aquellos más profundamente inmersos en una revolución tanto menos conscientes de su 
dinámica" (McLuhan, 1998, p. 158).

En otro sentido $y$, más allá del afecto o antipatía que se profese a la multinacional Disney, podemos coincidir en la capacidad innovadora que ha demostrado esta empresa para experimentar y alcanzar con sus extensiones todas las fórmulas y formatos posibles (imaginables o inimaginables), incluso, de inventar su propio transmedia antes de que existiera. Sin ir más lejos, el proceso de storyboarding fue desarrollado en los estudios Disney a principios de los años '30 del siglo XX. En lo que respecta a la emoción y la generación de entusiasmo Disney es conocido por despertar ilusiones perdidas, además de abarcar todo tipo de entornos y medios a partir de los que se expande el relato. Un referente de esta estructura reticular son los parques temáticos, donde los personajes animados se transforman en sujetos reales que interactúan con el público.

La pantalla siempre ha sido una imposición en la que los personajes estaban encerrados en un marco forzado. Como hemos visto, en algunas producciones infantiles esta limitación no es tal, (la estrategia montada alrededor del producto se corporiza como estrategia de marketing, los personajes se escapan de la pantalla para formar parte de otros escenarios: centro comercial, parque temático, etc.) ya que consigue una inmersión más allá de la pantalla y aprovecha para resaltar el papel social de un mundo hipermediático donde la narrativa adquiere giros que pueden despertar o adormilar conciencias. Habremos de estar vigilantes para descubrir el poder que ostentan los fuertes oligopolios que controlan el mundo y, que a través de su influencia mediática, consiguen una concienciación colectiva utilizando técnicas provocadoras que van desde el mensaje inmerso en la fotografía estática hasta el happening artístico donde se amalgama el dibujo animado con la "participación" callejera.

Desde diferentes perspectivas se aplican metodologías didácticas que utilizan estos recursos audiovisuales en la educación formal; sin embargo, difícilmente se aborda la dimensión psicopedagógica de esta cuestión. Menos aún, en estos momentos en los que las narrativas discurren por ámbitos y medios poco conocidos por el profesorado, donde la falta de instrumentos de análisis crítico dificulta la aplicación de disciplinas educativas en el aula. Por tanto, nuestra intención -en posteriores estudios- consistirá en ofrecer estrategias metaficcionales que cuestionen las actuales narrativas a la vez que ofrezcan a las instituciones académicas metodologías didácticas más cercanas a la realidad actual, buscando en las redes sociales, el cine infantil o en los relatos creados por las personas usuarias de la red aquellas posibilidades que ya apuntara el happening cuando dejaba la puerta abierta a la expresión y la creatividad.

La democratización del cine y otras acciones artísticas han logrado que la narrativa digital tenga un sitio en la escuela. Gracias a la imaginación y la creatividad, el acto de crear historias significativas surge para incrementar las experiencias del alumnado y el profesorado. No obstante, las diversas narraciones digitales en las que encontramos héroes y heroínas infantiles rezuman una intencionalidad ideológica que, aunque 
invisible, deja obras con un mensaje hipnotizante que traslada a la infancia a épocas pasadas. Sus apariciones y mensajes no son fortuitos ni inconexos porque sus estéticas están estudiadas hasta el último detalle. Se establecen conexiones o vínculos con otras versiones y son transformaciones aparentes de la creación original, convirtiéndose en un sistema reticular que las mantiene sujetas, cual cordón umbilical, a la idea referente primaria y a las ideas supletorias que irán proliferando entre las mentalidades infantiles, calando y acoplándose en un encaje perfecto que se implantará como un chip de memoria a partir del cual las criaturas se irán formando a imagen de cyborgs de una sociedad transmedia. Nuestro reto consiste en descubrir este adoctrinamiento impuesto y reivindicar la libertad del ser humano en esta incipiente clonación mercantilista.

Grandes multinacionales como Disney, en su esencia empresarial, anteponen su lógica comercial a los contenidos educativos. Sin embargo, al carecer los centros de enseñanza de materiales didácticos propios para la alfabetización mediática utilizan los producidos por estas empresas sin reparar en que se están empleando los mismos parámetros que deberían ser puestos en tela de juicio para afrontarlos desde una perspectiva crítica, con lo cual, estamos promocionando desde las escuelas una Disneyzación de la cultura infantil.

The Walt Disney Company, como oligopolio mediático, se convierte en la mayor factoría de contenidos audiovisuales que monopoliza toda la audiencia infantil. Desde cadenas de televisión, editoriales de cómics, etc. se nombran empresas como: DisneyABC Television Group, Walt Disney Studio Entertainment, Marvel Entertainment, teatro New Ámsterdam de Broadway, Disney Stores, Pixar, Time Warner Cable, Tochstone Television, ESPN.com, Miramax Films, DreamWorks, etc. Desplegando una estrategia mediática que no le supone ningún tipo de riesgo "comercial". Al no existir competencia en el ramo, ni alfabetización audiovisual, se convierte en la única opción posible de entretenimiento infantil. Además de estar ubicadas en un sector en expansión que contrarresta con la actual crisis económica característica de otros ámbitos empresariales.

De este modo añadimos también la connotación mercantilista como área de análisis del estudio de la narrativa digital que, sobre todo en el cine de animación infantil constituye un obstáculo más para su focalización científica.

\section{CONCLUSIONES}

El happening artístico se planteaba como una alternativa para dar voz a la creatividad individual, pero vimos que rápidamente la masa calló y cayó (en el silencio y en el olvido). La posibilidad de transformar al mundo se tornó cultura de masas y, con ella, reprodujo la voz opresora. En palabras de Paulo Freire (2005) "Mas si decir la palabra verdadera, que es trabajo, que es praxis, es transformar el mundo, decirla no es privilegio de algunos hombres, sino derecho de todos los hombres" (Freire, 2005, p. 


\section{1).}

La naturaleza dinámica de la narrativa transmedia vuelve a colocarnos como autoras de nuestra historia, esta vez digital, para que co-creemos un mundo múltiple desde la infancia, pero igual que el happening nos planteó ciertas dudas, a lo largo del texto hemos ido presentando espacios desde donde aproximar historias al público (infantil) y en las que éste no siempre ha tenido la posibilidad de participar. Nos hemos preguntado por las diferencias y semejanzas de las imágenes y los discursos y, hasta qué punto, podrían ser analizadas para apropiarnos de los relatos.

Los cuentos, igual que el cine y los juegos construyen la identidad infantil, pero ¿nos hemos detenido a pensar cuáles son las técnicas - de excitación afectiva- que se encuentran insertas en los discursos actuales?, cestamos educando para dar una respuesta cultural o serán las multinacionales quienes se encarguen de culturizar a la infancia?. Además, ¿cómo interactúan las niñas y niños con estas narrativas?, ¿reproduciendo lo conocido? y todo ello ¿está apoyado por el desconocimiento del que se saben cómplices progenitores y enseñantes?

Este artículo fue acometido para cuestionarnos la apropiación que se puede hacer de los relatos infantiles, nuestra intención no consiste en mostrar un catálogo de recursos para estudiar la narrativa digital en la infancia, sino plantear cuestiones con las que desnaturalizar este tipo de ficciones para que, mediante la educación, la participación, la transgresión, la lectura perversa y la mirada alternativa y disidente (Correa, 2011) recobremos el derecho a tener voz en nuestras historias, evitando ser deslumbradas, una vez más, por ¿estos indicios de libertad?

\section{REFERENCIAS}

BARTHES, R. (2009). El susurro del lenguaje. Más allá de la palabra y la escritura. Barcelona, España: Paidós.

BELTRÁN, J., PEÑA, A., PÉREZ, L. y ANDRÉS, T. (s.f.). "El impacto de la comunicación audiovisual en la modificación conductual y cognitiva de los niños, en la Comunidad de Madrid" (Investigación) Disponible en: http://tv mav.cnice.mec.es/impacto.htm (Recuperado el 29 de junio de 2015).

BOURDIEU, P (2000). La dominación masculina. Barcelona, España: Anagrama.

CANTILLO, C. (2010). Análisis de estereotipos sexistas. Perpetuación de roles de género en la filmografía de Disney: de la ingenua Blancanieves (1937) a la postmoderna Tiana (2009). Madrid. UNED. (Trabajo Final de Máster Educación y Comunicación en la Red). Disponible en: http://trabajofinmaster.pbworks.com/

CORREA, R.I. (2011). Imagen y control social. Manifiesto por una mirada insurgente. Barcelona, España: Icaria. 
DORFMAN, A. y MATTELART, A. (1972). Para leer al pato Donald. Comunicación de masas y colonialismo. México: Siglo XXI editores, S.A.

ECO, U. (1879). Lector in Fabula. La cooperazione interpretativa nei testi narrativi, Milán, Italia: Bompiani.

FREIRE, P. (2005). Pedagogía del oprimido. México: Siglo XXI.

GIROUX, H. A. (1996). Placeres inquietantes. Aprendiendo la cultura popular, Barcelona, España: Paidós.

GIROUX, H. A. (2001). El ratoncito feroz: Disney o el fin de la inocencia. Madrid, España: Fundación Germán Sánchez Ruipérez.

JENKINS, H. (2009). Fans, blogueros y videojuegos. La cultura de la colaboración. Barcelona, España: Paidós.

LIPOVETSKY, G. Y SERROY, J. (2009). La pantalla global. Cultura mediática y cine en la era hipermoderna. Barcelona, España: Anagrama.

MARÍN, J. (2009). Cine de dibujos animados. Argentina: El Cid Editor.

MCLUHAN, M. (1967). The Medium is the Masaje. UK: Penguin Books Limited.

MCLUHAN, M. (1998). La Galaxia Gutenberg: génesis del Homo Typographicus. Barcelona, España: Círculo de Lectores.

MENDOZA, A. (2012). Leer hipertextos. Del marco hipertextual a la formación del lector literario. Barcelona, España: Octaedro.

MONTOYA, V. (2003). Literatura infantil. Lenguaje y Fantasía. Bolivia: La Hoguera.

MORIN, E. (1956). El cine o el hombre imaginario. Barcelona, España: Paidós.

ORTEGA Y GASSET, J. (1937). La rebelión de las masas. Disponible en: http://literatura.itematika.com/bajando.php?path=descargas/libros\&name=larebelion-de-las-masas.pdf

PEREIRA, C. (2005). Los valores del cine de animación. Propuestas pedagógicas para padres y educadores. Barcelona, España: PPU.

PROPP, V. (2006). Morfología del cuento. Madrid, España: Fundamentos.

SALMON, C. (2010). Storytelling. La máquina de fabricar historias y formatear las mentes. Barcelona, España: Península. 
SCOLARI, C. (2013). Narrativas transmedia. Cuando todos los medios cuentan. Barcelona, España: Planeta.

\section{AUTORA}

\section{Carmen Cantillo Valero}

Profesora de Comunicación y Educación en la Red en la Universidad Nacional de Educación a Distancia (UNED). Doctoranda en Educación y Comunicación en Entornos Virtuales en UNED, desarrollando la tesis "Imágenes infantiles que construyen identidades adultas. Los estereotipos sexistas de las princesas Disney desde una perspectiva de género para comprobar sus efectos a través de las generaciones y en diferentes entornos: digital y analógico".

Correo: carmen.cantillo@invi.uned.es 